DEVICES FOR USE IN FISH HATCHERIES AND AQUARIA $* * * * *$

From BULLETIN OF THE BUREAU OF FISHERIES, Volume XXVII, IgOS Procedings of the Fourth Intemational Fishery Congress: Washington, 1qu8

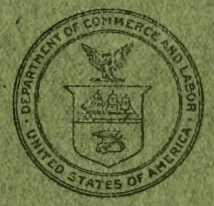

WASHINGTON : : : : : : GOVERNMIENT PRINTING OFFICE : : : : : : 1910 


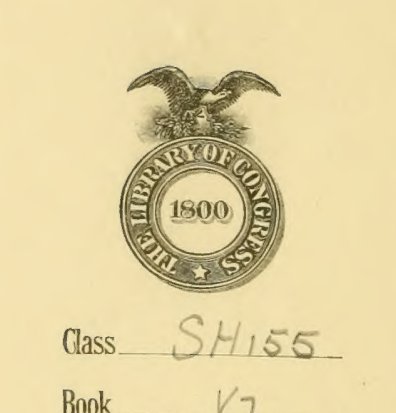






\section{DEVICES FOR USE IN FISH HATCHERIES AND AQUARIA * $*$ \\ * \\ $\infty$ \\ *}

From BULLETIN OF THE BUREAU OF FISHERIES, Volume XXVIII, rgos Procee@igs of the Fourth Intemational Fishery Congress : : Washington, Igo8

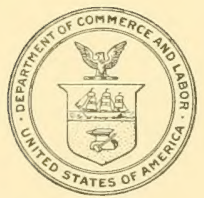

WASHINGTON : : : : : : GOVERNMENT PRINTING OFFICE : : : : : : 1910 


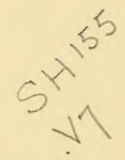

BUREAU OF FISHERIES DOCUMENT NO. 705

Issued April, 1910

\author{
APF 301910 \\ D. O\& B.
}




\title{
DEVICES FOR USE IN FISH HATCHERIES AND AQUARIA
}

\section{2}

\author{
By Eugene Vincent
}

Fish Culturist, Aquarium of the Trocadero, Paris

$x$

Designs presented before the Fourth International Fishery Congress held at Washington, U. S. A., September 22 to 26, 1908 


\section{CONTENTS.}

$*$

Page.

Artificial pond with siphoid outlet for regulation of height of water $\ldots \ldots \ldots$

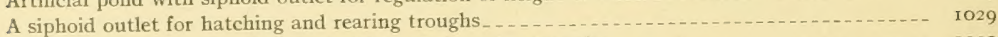

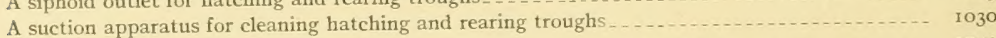

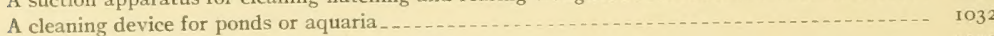

Oxygenation and vacuum-producing apparatus _ .

Scraper for preparing fish food

1026 


\title{
DEVICES FOR USE IN FISH HATCHERIES AND AQUARIA.
}

\author{
* \\ By EUGENE VINCENT, \\ Fish Culturist, Aquarium of the Trocadero, Paris.
}

$*$

[Translated from the French.]

ARTIFICIAL POND WITH SIPHOID OUTLET FOR REGULATION OF HEIGHT OF WATER.

This pond is made of cement, the bottom having a layer 0.05 meter in thickness and a lining of 0.02 meter, the sides being 0.08 meter in thickness. The dimensions are $\mathrm{I}_{2}$ to $\mathrm{I} 5 \mathrm{me}$ ters by 3 meters, with any desired depth, and the ends are rounded. Crosswise the bottom slopes from the middle upward at the degree of 0.05 meter per meter, which equals 0.75 meter for a side of 1.5 o meter. With this slope the pond may be cleaned by simply sweeping toward the center or by means of a few buckets of water thrown against the sides. It is fed by one or more troughs which empty into it with a stream of 0.20 .

The pond must be level in lengthwise direction, in order to preclude danger of leaving any dry area below a given height. In the middle of the bottom of the pond, beginning at the intake end and terminating in a circular
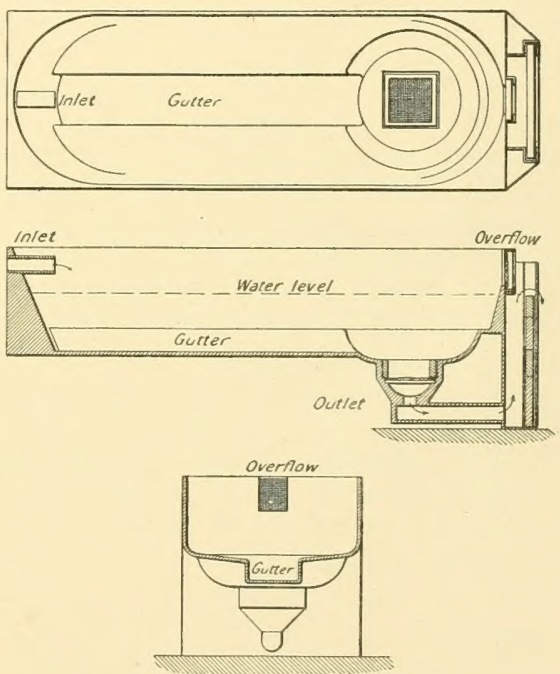

Fig. 1,-Design for artificial pond with siphoid outlet.

basin which occupies the opposite end, is a gutter at least 0.50 meter in width and 0.12 to o.I 5 meter in depth. The circular basin is from 1.50 to I.80 meters in diameter, and 0.20 to 0.30 meter in depth. With the gutter it serves to hold 
the fish when the water is drawn out of the rest of the pond for cleaning. The cleaning process itself is simplified, since a man may enter for the purpose and walk about on the bottom of the pond.

So far the pond is not provided with any outlet. In the wall opposite the intake, O.I 5 or 0.20 meter above the gutter in the bottom of the pond, is an aperture 0.50 to 0.60 meter square, covered with wire netting. This, however, is not an outlet but an overflow. The outlet proper is in the bottom of the large circular basin and consists first of an opening o.6o meter square and o. I o to o. I 2 meter deep. Into this square is set a wooden box with a wire mesh bottom, and this box, filled with coarse gravel, rests upon an iron grating 0.60 by 0.60 meter. Below the grating is a circular basin 0.50 meter in diameter and 0.15 meter in depth, with an opening in the center which leads into an outflow pipe.

The outlet provided, the regulation of the water level in the pond remains to be accomplished. This is done by carrying the outflow into a tank or other receptacle outside the pond, in which any desired level may be maintained by regulation of its overflow. The latter is controlled by a board wall or dam constructed of removable sections.

In addition to the convenience of this construction in regulating the height of water in the ponds, there is afforded every protection against loss of the small fish, since the water in leaving must pass through gravel the size of hazel nuts; the cleaning of the pond may be accomplished without injury or shock to the fish; all impurities fall into the gutter and are carried off through the circular basin, while the fish, seeking the incoming current, are in the upper strata of water and away from all such impurities as do not pass through the screened outlet; the fish are provided with desirable currents derived from the action of the siphon, and the pond is continuously self-cleaning. When the fish are larger the gravel may be removed, and still later the screen itself may be discarded.

Fish culturists will appreciate the importance of perfect control of their rearing ponds. A construction such as this described is possible wherever there is a fall of at least $\mathrm{I}$ meter in the water supply, since it is not necessary to take the siphon apparatus into account. There is but one thing absolutely necessary to provide against-namely, the possibility of emptying the pond entirely, down to the screen with the gravel. It is of little importance that the outflow pipe is not emptied; the water will always flow off, on account of the difference of level.

The design has been adopted with satisfactory results in several fish culture establishments in France. 


\section{A SIPHOID OUTLET FOR HATCHING AND REARING TROUGHS.}

The various systems of outlet in most fish-cultural equipment are defective in several ways, as I have had occasion to observe on visits to different establishments. The young fish escape in the outflow, perhaps, due to its faulty construction or installation; many of them are caught in the perforations of the sheet-iron cap and die there; many others are killed or injured by the fingers that try to rescue them; overlows are caused by the clogging of the perforations; the water is not thoroughly renewed and the trough becomes infected with germs of disease. All this is too familiar to need to be dwelt upon. I have sought to overcome various difficulties by the following device.

I have provided a large cylindrical wire screen or cage, which is set over the outlet and incloses the outlet apparatus which I shall describe. The large surface of the screen gives free course to the water without attracting the young fish and thus becoming a means of their destruction.

In the daily procedure of changing the water in the rearing troughs, I desire to be able to lower the level to a given point without the necessity of losing time waiting beside the trough. To accomplish this I have made, first, for the orifice in the bottom of the trough, a water-tight collar of two pieces screwed together

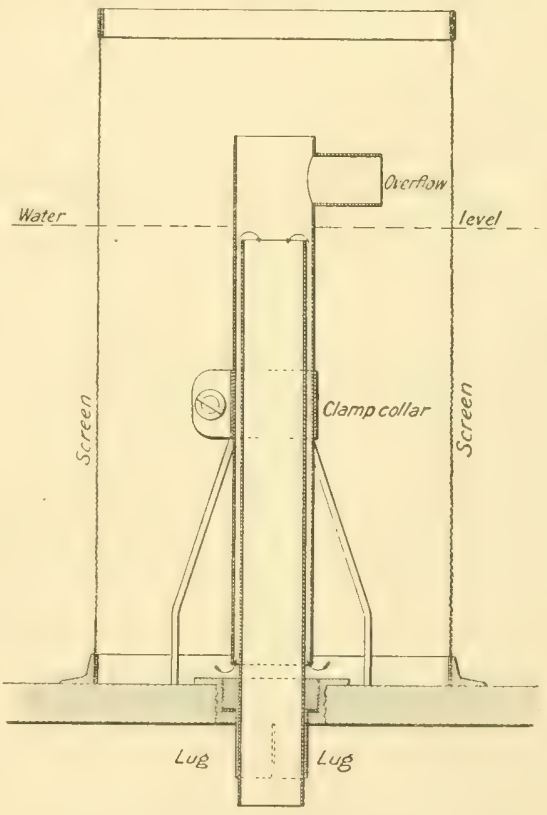

F1G. 2.-A siphoid outlet for hatching and rearing troughs. with a leather washer between. The lower piece is supplied with lugs extending downward, and into this collar is inserted a tube, making an ordinary standpipe. With this form of outlet, however, the water is renewed only at the surface, the bottom water, with remnants of food, refuse substances, etc., being left unchanged. I have accordingly elaborated the standpipe into a form which constitutes an unfailing cleaning device. It carries off all the solid matter 
that passes through the screen, and affords a desired current for the young fish, which do not like to be inactive.

For this purpose a second slightly larger tube is slipped over the standpipe and, by means of a clamp collar supported on three legs, is held with its lower end just above the bottom. The current thus produced can be regulated, greater force being obtained when desired by lowering the outer tube and thus preventing the full outflow of water. This raises the level in the trough, and the difference between the level in the trough and the stream which can escapenamely, the height of the inner standpipe-makes the pressure to force the water up from the bottom and carry with it the refuse matter in the trough. It is not in a trough such as this that there will be ill-smelling bottom water.

The apparatus does not, as one might think, act merely as do communicating vessels. With a flow of 2 to 3 liters per minute I obtain a difference of level of 3 to 4 centimeters, according to the elevation of the outer tube. By regulation of this tube, which is very simple, both surface and bottom water will be renewed. If only the lower water were emptied an oily layer would form at the surface and act as an insulator between the air and the water.

As the aquarium of the 'Trocadero is supplied by sluices, in the flow of which there might be the same fluctuations as in the river, I have provided an emergency overflow to balance any sudden rush of water.

When it is desired to remove some of the fish from the trough the whole apparatus may be removed, the mouth of the outlet in the bottom of the trough being closed with an ordinary cap or plug.

\section{A SUCTION APPARATUS FOR CLEANING HATCHING AND REARING TROUGHS.}

This device is designed for use in the removal of dead eggs or fry, remnants of food, or any undesirable substance that may be found in the troughs. The use of the usual metal or wooden tweezers, or perhaps long pins, too often causes the eggs to burst, thus spreading infection from their decomposed contents. Little glass pipettes are used, taking one egg at a time. But this often escapes and, falling to the bottom of the trays, is left to give rise to Saprolegnia.

To meet these difficulties I have used a pipette with a rubber bulb attached. The tubes vary in diameter, according to the sizes of the different species of eggs, and are 0.25 meter long, being slightly bent at the entrance to the bulb. At the outer end is a ring of blue glass to guide the eye of the operator. With the aid of this form of pipette 15 or $20 \mathrm{eggs}$ may be taken up to be thrown out of the trough at one motion of the operator.

Upon this appliance as a basis I subsequently devised a second means of cleaning by combination with the siphon principle. The later apparatus 
consists of a long rubber tube attached, with metal handle and connections, to a blue-tipped pipette on one side and to a rubber bulb on the other. The bulb normally receives its air supply through a small rubber tube which is connected with a metal piston valve inserted in the large tube some 0.60 meter below the bulb. An auxiliary air valve in the handle is controlled by a little piston within reach of the index finger of the right hand.

To use this apparatus have the lower end of the large tube and also the lower piston valve below the water level existing in the trough. Squeeze the bulb with the right hand, press the lower piston with the left, and then, putting the end of the glass tube in the water, release the bulb. Then release the piston and the siphon will have started. The glass tube may be directed at will. If the suction is too strong it may be regulated by the piston in the left hand.

Should a good egg be picked up by mistake it may be readily replaced without waiting for it to discharge at the lower end of the rubber tube. Stop the flow of water by closing the lower piston with the left hand; then press the bulb to expel the air from the small tube upward into the larger, the mouth of the glass tube being meanwhile under water. If this does not force the egg out of the glass tube continue to hold the piston closed, squeeze the bulb with the right hand, and then with the index finger press the little auxiliary piston at the end of the handle. If now the buib is released it will fill. Removing then the pressure from the little piston on the handle there can be no escape of air at this

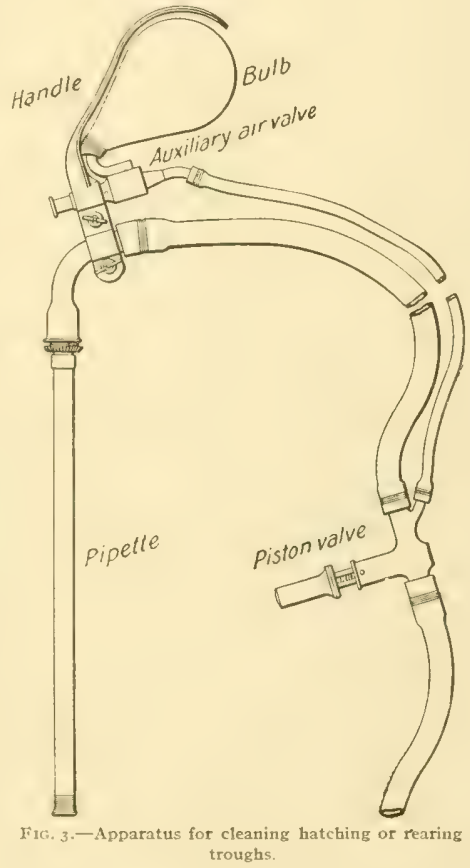
point when the bulb is compressed, but only backward in the main tube, for the discharge outward is cut off by the closed lower piston valve. The egg will thus be forced out of the glass tube.

Care should be taken to avoid drawing water into the bulb, but in such event a discharge may be effected by proceeding as just described except that the lower piston valve is in this case left open. 
This apparatus has proved most successful and obviates the necessity of putting the hands in cold water to do the work of picking the eggs.

A CLEANING DEVICE FOR PONDS OR AQUARIA.

The imperfect construction of some ponds, not permitting them to be entirely emptied, necessitates the use of various means and implements, such as dip nets and even shovels, for cleaning. With even the greatest care it is

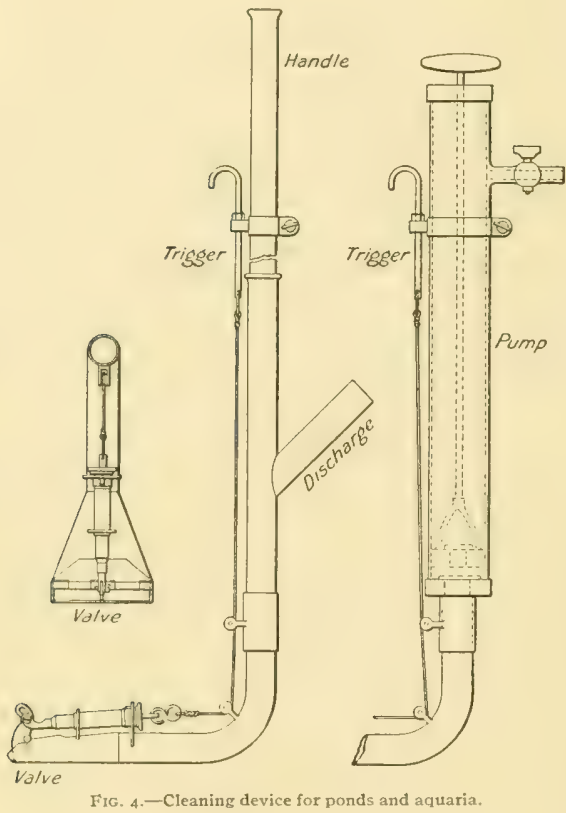
difficult to maintain the cleanliness necessary to avoid mortality among the fish.

The present device enables the fish culturist to prevent disease by more thorough cleaning, and also by avoiding the bruises inflicted upon the fish in the course of the ordinary cleaning process if the water is muddy. It also prevents the disagreeable taste of fish reared in muddy and ill-cleaned ponds.

The apparatus is constructed upon the principle of the foregoing rubber siphon and glass tube. Being for larger work, however, it is made of brass pipe with rubber or canvas connections. It consists of a main arm terminating in an elbow joint which is expanded into a flat triangular cavity with an entrance valve. This valve, opening upward, is controlled by a lever attached by a cord to a trigger on the handle of the apparatus. The handle, which is of wood and inserted in the upper end of the main tube, may be of any desired length. Branching off the main tube a short distance below the handle is an arm for connection with the discharge pipe.

In operation the discharge arm may be attached to rubber or canvas hose, with outlet below the level in the pond or tank, and the apparatus guided about over the bottom by means of the handle, the suction being regulated by the cord attached to the valve. In cases where the pond may not be emptied, 
and the siplon therefore is not feasible, the handle is removed from the cleaning apparatus and a pump attached. A small suction pump, such as used in gardens, is very suitable. If for any cause convenient, the apparatus may be left in the pond, for with the valve closed the suction can not act.

OXYGENATION AND VACUUM-PRODUCING APPARATUS.

This apparatus is in effect a section which may be introduced into a supply pipe, and consists of an exhaust chamber and an air-supply tube, with the essential feature of a movable jet. The differences of water pressure and sizes of supply pipes render a stationary jet ineffective or even useless at times.

The model here represented has a jet of 5 to 6 millimeters diameter, adjustable by means of a screw on the outside, and sends air into the water to a depth of about 4 meters, from an opening of 20 millimeters. It may be mounted with openings varying from 20 to 26 millimeters. The lower part of the apparatus is provided with a movable tube having a conical entrance, to divide the water better and make the vacuum stronger.

The pressure of the water of the Vanne is diminished in the sluices of the Trocadero Aquarium by the many separate outflows, and to provide the desired currents, I 3 of these oxygenators have been installed. The fishes playing in the numerous silvery bubbles which rise from the bottom arouse much admiration from the public, and it will be readily believed that the fish are clean and never sluggish. Small or large, they thrive with this kind of aeration, which brings them artificial currents of water which they did not find in these same ponds before. These currents, moreover, do not allow the food given to fall to the bottom when it is sprinkled in. The young fish, some 5 or 6 weeks old, may be seen to catch in passing the small particles of food which the water brings them. The ponds are from 2 to 3 meters deep, from 7 to 8 meters long, and from 2 to 3 meters

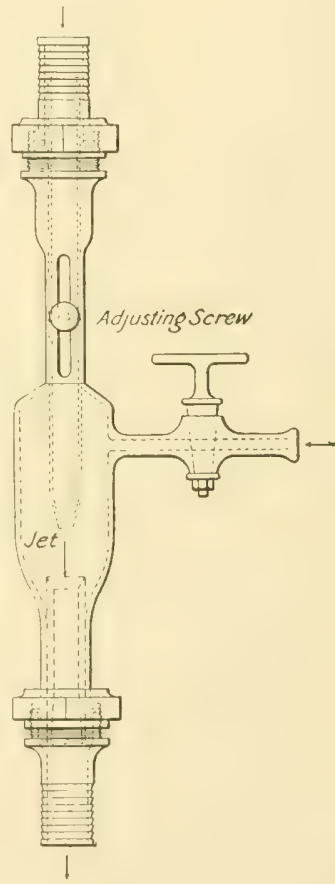

Fis. 5--Oxygenator and vacuum producer. wide. These oxygenators render great service; it is a hygienic method which ought to be used wherever possible.

This apparatus may be used without disarrangement for the purpose of producing a vacuum in boxes specially prepared for the preservation of food for fishes and even for the shipment of fishes destined for market. It may be 
of various sizes and may be placed at the base of a reservoir or even in a receptacle in an automobile for the transportation of fishes alive. In this case the motor will turn a small pump in the apparatus and this even during stops, with the exception of cases when the motor itself does not work.

I have a small oxygenator at the extremity of a small hand pump, to serve me for long transportations. This is more practical than an air pump, the globules from which are too large and must be divided. By means of its water jet, which carries the air along, the oxygenator divides its globules, and these rising less rapidly to the surface, aerate the water much better than the large globules.

The discharge pipe of the oxygenator must be sufficiently large to contain at the same time the air and the water which must pass through it together. Thus if it should be found necessary, as for instance, if the ponds need to be cleaned by flushing, it is possible to attach at the connection of the air pipe a joint identical with the water pipe and use this double water supply in spite of the presence of the oxygenator which might seem to intercept it. Or the spigot of the air pipe may be closed and the flow of water is then normal.

Some three years ago I placed with a manufacturer a design for an oxygenator, but feeling some distrust withheld the feature of the sliding jet, though I mentioned it. It was well that I did withhold it, for not only did I lose my apparatus but the idea was stolen, though I retained the secret of the true mode of operation. The sliding jet is indispensable to success. In a locality in the north of France a system of oxygenators installed at great expense afterwards necessitated the modification of a great part of the plumbing and changes in the size of jets, all of which is obviated by the sliding jet.

\section{SCRAPER FOR PREPARING FISH FOOD.}

Fish culturists know that it is not a very agreeable or easy task to extract the pulp from the spleen of horses or beeves, and that it is, moreover, a very long and fatiguing operation if a knife, spoon, or any such instrument is used. For my part, having some 15 kilograms and sometimes more of spleen to scrape, I endeavored to find a readier means.

My device somewhat resembles a block plane in shape, with 5 blades protruding their full depth. I had to seek a long time for blades of requisite flexibility, shape, and size, and to fit them in proper place and at proper inclination. It will be seen that these blades have not all the same shape. This is because each has its definite place of contact, none scraping directly on the spot which the preceding blade has scraped. Otherwise the pulp would be immediately torn at the first stroke of the scraper. I have likewise overcome the other difficulties encountered at the beginning of the attempt at this device.

The following is the mode of proceeding: 
To a board, I meter long and 0.30 meter wide, edged with a strip 0.02 meter high to keep the pulp of the spleen from falling over the sides, is affixed at each end a transverse support to raise it above the surface of the table on which the scraper is used. One support should be sufficiently high to permit a small receptacle to be placed somewhat under the board, at a height of o.ro meter approximately, while for the other support a height of 0.03 meter would be sufficient. The board will thus be inclined.

At the lower end a narrow board is attached flat by means of a hinge at the farther side. This small board is 0.05 to 0.06 meter wide, of the same thickness as the big board, and in it are fixed Io to 12 sharp points 0.02 meter long, spaced 0.015 meter apart. This board swung back, the spleen is placed flat on the larger board, some 0.03 or 0.04 meter of it falling over the end. The small board is then swung forward and its points, piercing the spleen, will keep the latter in place during the scraping. A small hook at the end holds the small board in position to keep the spleen from slipping. The thin skin around the spleen is taken off with a knife and the spleen is cut longitudinally several times.

The scraper is manipulated in the manner of a plane. The spleen should be turned end for end, if need be, to scrape the part which had been held under the
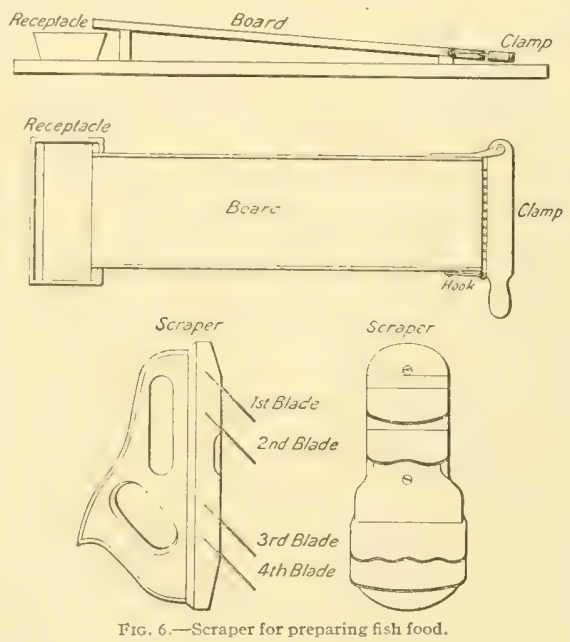
toothed board.

This implement may seem an odd device, but it is remarkable how rapidly the spleen pulp is extracted. Two to three minutes are sufficient for the operation, with a spleen weighing o.80 kilogram. It should be added that this pulp does not contain any remnants of spleen cells, as might be supposed.

If the spleen is frozen in winter and it is not feared that the nutritive qualities of the raw flesh or the spleen pulp might be decreased, it may be immersed for a few minutes in hot water before being scraped and the operation will be still more rapid.

Several establishments make use of this scraper because their proprietors have seen me use mine. I have ordered several from a manufacturing firm. 






